\title{
MULHERES E HOMENS JOVENS: GOZOS E INTERDIÇÕES, PODER
} E DESIGUALDADES

JÓVENES DE AMBOS SEXOS: PLACERES Y PROHIBICIONES, PODER Y
DESIGUALDAD
YOUNG WOMEN AND MEN: ENJOYMENTS AND INTERDICTIONS,
POWER AND INEQUALITY

http://dx.doi.org/10.1590/1807-0310/2017v29153790

Karla Galvão Adrião, Jaileila de Araujo Menezes e Leyllyanne Bezerra de Souza

Universidade Federal de Pernambuco, Recife/PE, Brasil

Raissa Falcão

Faculdade Estácio do Recife, Recife/PE, Brasil

\section{RESUMO}

Este artigo discute sobre as relações de poder e desigualdades que atravessam os modos de subjetivação de homens e mulheres jovens participantes de um projeto de pesquisa-intervenção em um território em "desenvolvimento econômico". Referenciamo-nos nos campos da Psicologia Social e das Teorias Feministas e de Gênero PósEstruturais, em uma perspectiva teórico-metodológica de trabalho com grupos. Analisamos dois recortes temáticos de oficinas acerca de sexualidade e sociabilidade/trabalho-lazer. Os sentidos a respeito de sexualidade ganharam forte conotação de gênero, com destaque para o uso da qualificação moral "safadeza" quando a dinâmica sexual das mulheres rompe com o comportamento de comedimento. Tais desigualdades atravessaram também os sentidos sobre trabalho-lazer; os homens são posicionados como aqueles que merecem gozar de tempo livre. Apesar da aparente rigidez, outros sentidos ligados às dinâmicas de gênero foram construídos pelo grupo, o que tornou possível a produção de posicionamentos mais críticos e subversivos.

Palavras-chave: juventudes; teorias feministas; gênero; sexualidade; sociabilidade.

\section{RESUMEN}

Este artículo discurre sobre las relaciones de poder y desigualdad que atraviesan los modos de subjetivación de jóvenes hombres y mujeres participantes de un proyecto de investigación-intervención en un territorio en "desarrollo económico". Hacemos referencia a los campos de la Psicología Social y a las teorías Feministas y de Género Post-estructurales, en una perspectiva teórico-metodológica de trabajos con grupos. Analizamos dos recortes temáticos de talleres sobre sexualidad y sociabilidad/trabajo-ocio. Los sentidos sobre sexualidad han incorporado fuerte connotación de género, destacando el uso de la calificación moral "safadeza" cuando la dinámica sexual de las mujeres rompe con el comportamiento de comedimiento. Dichas desigualdades abarcaran también los sentidos sobre trabajo-ocio; los hombres son posicionados como los que merecen disfrutar de tiempo libre. A pesar de la aparente rigidez, otros sentidos vinculados a las dinámicas de género han sido construidos por el grupo, lo que ha hecho posible la producción de posicionamientos más críticos y subversivos.

Palabras clave: juventud; teorías feministas; género; sexualidad; sociabilidad.

\begin{abstract}
This article discusses the relations of power and inequality that cross the modes of subjectivity of men and young women participating in a research-intervention project in an area in "economical development". The reference of this work is in the fields of Social Psychology and Post-Structural Feminist and Gender Theories, in a theoretical and methodological perspective of working with groups. We have analyzed two thematic cutouts of workshops on sexuality and sociability/work-leisure. The senses of sexuality gained strong gender connotations, especially the use of moral qualification "naughtiness" when the sexual dynamics of women breaks with the behavior of moderation. These inequalities also crossed way about work-leisure, in which men are positioned as those who deserve to enjoy free time. Despite the apparent rigidity, other senses linked to gender dynamics were built by the group, which made it possible to produce more critical and subversive positions.
\end{abstract}

Keywords: youth; feminist theories; gender; sexuality; sociability. 


\section{Introdução}

Este artigo tem como propósito ampliar a discussão sobre processos de subjetivação e sua interface com relações micro e macro, a partir do diálogo com a literatura acerca de feminismo, gênero e Psicologia social, tendo como base os resultados de uma pesquisa-intervenção. Mais especificamente, pretendemos refletir a respeito das relações de poder e desigualdade de gênero, classe e território e seus atravessamentos nos processos de subjetivação de homens e mulheres jovens moradores de uma região submetida a "processo de desenvolvimento econômico".

De forma implícita, o presente artigo busca refletir sobre a interface entre dois campos de estudos. Por um lado, o da Psicologia social, tematizando processos de subjetivação, e o uso da pesquisa-intervenção como campo teórico-metodológico que dialoga com metodologias participativas de trabalho com grupos. E, por outro, o campo dos estudos feministas e de gênero, especificamente com relação a como algumas teorias feministas de micro e macro análise podem apresentar leituras alternativas não apenas sobre, mas com populações jovens e minoritárias em situação de desigualdade de classe, gênero e território.

Portanto, para a consecução deste trabalho, fundamentamo-nos no debate feminista pós-estrutural (Butler, 2004; Haraway, 1995) quanto ao uso do gênero e de outras categorias de desigualdade, a partir da noção de interseccionalidade (Nogueira, 2011; Piscitelli, 2008). Interessa problematizar os efeitos das situações de desigualdade nos processos de subjetivação de e com jovens. Além disso, tomamos como aporte teórico o campo do pós-estruturalismo na interface com a psicologia social no contexto da pesquisa-intervenção, de trabalho com grupos (Fine et al., 2006; Palombini, Maraschin, \& Moschen, 2012; dentre outros) e de processos de subjetivação (Costa, 1989; Foucault, 2006; dentre outros).

Tais postulados teórico-metodológicos serão abordados a partir das vivências de jovens de ambos os sexos, em contexto de desigualdades, que participaram do projeto de pesquisa-intervenção chamado "Ação Juvenil". Compreendemos juventude como um momento biográfico (Serafim \& Bonini, 2015), que não se reduz a uma passagem, assumindo uma importância em si mesma através de suas experiências de participação social. A vivência da juventude é influenciada pelo meio social concreto e pela qualidade das trocas que este proporciona, fazendo com que os/ as jovens construam diversos modos de ser e de existir (Carrano, 2000).
A elaboração desta compreensão resulta do reconhecimento das tensões e disputas presentes no campo de pesquisa-intervenção juventude. Abramo (2005) apresenta algumas tentativas de resposta à complexidade do debate sobre a distinção entre os termos condição e situação juvenil. O primeiro recobriria o significado social construído pela dimensão histórica e geracional. A situação juvenil, por sua vez, faria referência ao modo como a condição é vivida a partir das diferenças sociais de classe, gênero, território, orientação sexual, entre outras.

Sem dúvida, o debate sobre a diversidade juvenil colaborou com a crítica a compreensões universalistas, homogeneizantes e biologicistas. Na psicologia, tais compreensões marcam a perspectiva evolucionista que produz associações entre adolescência e juventude via insígnias da desqualificação (o que ainda não é; etapas que ainda não cumpriu; crises próprias à idade). Contemporaneamente conseguimos localizar uma série de estudos na área que rompem com a perspectiva evolucionista e afirmam epistemologias críticas às relações de poder e desigualdade que marcam a construção das relações sociais e etapização da vida (Fine \& Fox, 2013; Menezes, Costa, \& Santos, 2013).

Posicionar os/as jovens como edificadores/ as do mundo no aqui e agora de suas possibilidades de ação e entendimento da vida social é uma atitude fundamental em metodologias participativas e reflexivas, que convocam o/a pesquisador/a à produção de conhecimento crítico e politicamente engajado.

Em nossa trajetória, dedicamo-nos, desde o ano de 2008, a estudos sobre gênero e feminismo tendo como aporte a perspectiva da pesquisa-intervenção, e tomando tanto as teorias quanto as metodologias participativas como possibilidades de reflexão sobre/ com a realidade de jovens em sua complexidade interseccional. Nos resultados das pesquisasintervenções anteriores realizadas junto a mulheres jovens, em Recife, Cabo de Santo Agostinho, Ipojuca, e do Sertão Central de Pernambuco; bem como junto a mulheres e homens jovens dos bairros populares urbanos, e de regiões em "desenvolvimento econômico"; as desigualdades de gênero, geração, classe e território ganham relevo enquanto atravessamentos nos/dos processos de subjetivação e trajetórias afetivosexuais dos/as jovens (Quadros, Adrião, \& Xavier, 2011). Entretanto, na literatura nem sempre tais marcadores estão correlacionados ao debate a respeito do poder, particularmente no campo da Psicologia (Neves \& Nogueira, 2003; Toneli, Adrião, \& Perucchi, 2013). Pretendemos problematizar estas questões, particularmente a partir dos sentidos produzidos pelos/ as jovens sobre processos de subjetivação sexual e 
sociabilidades/trabalho-lazer vivenciados em território em "desenvolvimento econômico".

Para este artigo, discutiremos acerca da pesquisaintervenção "Ação Juvenil", projeto vinculado ao Programa "Diálogos para o Desenvolvimento Social em Suape" o qual se constituiu a partir de avaliações em torno dos impactos derivados do processo de instalação de um conjunto de empresas de grande porte na subregião pernambucana, que compõem o complexo Suape. O Programa surge como meio de investigar e intervir sobre agravos causados na dinâmica social da região tendo em vista as mudanças que o complexo industrial produziu no território existencial.

De modo específico, o "Ação Juvenil" consistiu em trabalho voltado à população jovem das cidades de Cabo de Santo Agostinho e Ipojuca, componentes da sub-região Suape. Apostando na potência política da juventude, mulheres e homens jovens foram convidados/convidadas para participar de ações de sensibilização e, posteriormente, formação continuada em temas relativos à saúde e à violência. Caracterizado como projeto de pesquisa-intervenção, o Ação Juvenil tinha como objetivos: (a) investigar os significados sobre a noção de desenvolvimento na relação com as desigualdades locais vividas por jovens; e (b) formar e instrumentalizar os/as jovens, de 16 a 19 anos de idade, enquanto lideranças capazes de atuar na produção e disseminação de informações qualificadas nos campos dos direitos da criança e do adolescente, saúde sexual e reprodutiva, e no enfrentamento a agravos de saúde e violações de direitos.

A formação continuada dos/as jovens teve o intuito de sensibilizá-los/as nas questões do programa mais amplo e construir, junto com eles/as, uma discussão das temáticas referentes à violação dos direitos da juventude e ao acesso à cidadania, integrando os/as jovens em ações junto às comunidades envolvidas no Programa Diálogos, denominadas "Caravanas da Cidadania". Buscou-se construir um formato para o trabalho que pudesse favorecer o lugar de sujeitos ativos aos/às jovens, no processo de pesquisa-intervenção, onde estes/as pudessem ter o poder de fala e possibilidades de construção de um conhecimento reflexivo acerca do cotidiano, tendo as metodologias participativas como ferramenta (McCarthy \& Galvão, 2001). A apropriação de técnicas de mobilização comunitária e da construção de narrativas críticas (comprometidas com a construção de sentidos históricos e desnaturalizantes) foi um potencializador da ação política dos/as jovens na cidade, pois em muitas situações favoreceu o conhecimento do território e localização das relações de poder que sustentam desigualdades sociais.
Esta formação continuada visava estabelecer relações mais igualitárias, possibilitando que as desigualdades de gênero, geração, classe e território pudessem ser problematizadas e refletidas em modos de subjetivação mais inteligíveis (Butler, 2004) para os/as jovens.

No presente artigo, abordaremos dois recortes temáticos (sobre sexualidade e sobre os cenários de trabalho-lazer), de momentos do grupo de formação ${ }^{2}$ em que tensões e conflitos vivenciados pelos/pelas jovens em seus territórios foram visibilizados e tematizados através dos efeitos de desigualdades sociais. O intuito de trazer tais recortes consistiu em descrever e analisar de que maneira os/as jovens participantes do projeto abordaram e (re)significaram as desigualdades às quais estão submetidos/as; e em que medida as metodologias participativas utilizadas auxiliaram eles/elas a identificarem relações de poder pautadas em gênero, classe, geração e território.

\section{Sobre o método}

O marco teórico-metodológico da pesquisaintervenção-pesquisa (Adrião, 2014) "Ação Juvenil" reconhece os processos de mudança das práticas individuais como enraizados coletivamente e marcados pela estrutura social (Paiva, 2002; Parker, 1998). Nessa linha, para que as análises a respeito das ações de promoção de igualdade no acesso à educação e saúde possuam os efeitos esperados, é preciso localizar os processos individuais frente a determinado agravo no plano sintético das situações de desigualdades sociais.

A pesquisa-intervenção-pesquisa foi conduzida em uma perspectiva qualitativa, de inspiração etnográfica, e teve como participantes os/as 20 jovens $^{3}$ das cidades de Cabo de Santo Agostinho e Ipojuca, sub-região de Suape, estudantes do ensino médio de escolas públicas. Tomaremos como dados indiretos para fins de contextualização do processo de produção de sentidos dos/das jovens - os roteiros de observações (diários de campo) dos 48 encontros/processos de formação e das 40 idas às comunidades na atividade "Caravanas da Cidadania", materiais produzidos (textos escritos, desenhos, colagens e audiovisuais) no grupo de formação do "Ação Juvenil" para atuação nas Caravanas. Os dados diretos foram extraídos das oficinas realizadas para a discussão das temáticas sexualidade e cenários de trabalho-lazer.

Na discussão, consideramos as contribuições da Psicologia Feminista (Fine \& McClelland, 2007; Neves \& Nogueira, 2003; Toneli, Adrião, \& Perucchi, 2013) com foco nas questões de poder (Butler, 2004) 
e de interseccionalidade (Nogueira, 2011; Pisciteli, 2008); e as abordagens da pesquisa-intervenção no campo da Psicologia propostas por Palombini, Maraschin e Moschen (2012) e Fine, Weiss, Weseen e Wong (2006).

\section{Interseccionalidades em ação: localizando desigualdades nas vivências sexuais e nos cenários de trabalho-lazer}

$\mathrm{Na}$ trajetória de pesquisa-intervenção-pesquisa, muitas atividades foram realizadas para envolver os/ as jovens no reconhecimento e enfrentamento de desigualdades que os/as afetam e também às suas comunidades, em especial as de gênero e sexualidade, a partir do marco dos direitos humanos, dando ênfase à problematização das relações de poder.

Um não menos relevante aspecto a se considerar concerne ao momento de intenso crescimento econômico pelo qual vem passando o Estado de Pernambuco. $\mathrm{O}$ aporte de recursos financeiros $\mathrm{e}$ investimentos que têm sido feitos no Estado estão provocando mudanças no cotidiano da população e têm demandado consultorias, controle social e realização de projetos que possibilitem que o crescimento econômico não se dissocie de relações igualitárias para as pessoas das comunidades, e em particular, dos/as jovens. As contribuições da psicologia social, do feminismo e de gênero comprometidos com a promoção da justiça social são imprescindíveis para qualificar criticamente projetos de pesquisa-intervenção em polos de desenvolvimento econômico.

Uma das contribuições diz respeito à atenção das possibilidades e níveis de participação dos diferentes atores/atrizes sociais envolvidos/as nos projetos. Entendemos que o envolvimento tem direta relação com problemas/questões que se almeja enfrentar. $\mathrm{Na}$ formulação da proposta do Programa Diálogos e do Projeto Ação Juvenil, vale comentar, primeiramente, acerca dos dados quantitativos que demonstraram um aumento do índice de violência sexual e de gênero, uso abusivo de álcool e outras drogas na sub-região SUAPE desde a chegada da Refinaria Abreu e Lima (UFPE/FADE, 2011). Acreditamos que tais dados informam sobre agravos vividos pela população a partir não só de uma linguagem matemática, mas também das dinâmicas políticas, das vulnerabilidades e (des)acordos sociais mais evidentes no território que corroboraram para a construção do Projeto.

Em segundo lugar, a formulação do Ação Juvenil passou por diferentes etapas de negociação no campo que também se ligaram ao grau de participação da comunidade. A primeira delas foi um curso de sensibilização, da equipe e das(os) jovens, chamado curso de Mídias Móveis, que teve a duração de dez dias no campo com a participaçao de 70 jovens da sub-região no formato de oficinas. $\mathrm{O}$ principal objetivo foi de posicionar os/as jovens como pesquisadores/as de seus territórios, proporcionando uma implicação político-afetiva via captação do cenário (macropolitica) e produção de cenas de seus cotidianos (micropolítica).

Por fim, ressaltamos a parceria com o projeto Caravanas da Cidadania, que promoveu mobilização comunitária mediante ações de rua com técnicos dos serviços da rede municipal de saúde, assistência e educação, além dos/as jovens do Ação Juvenil, somada à equipe universitária (UFPE). No entanto, é importante mencionar que essas ações/negociações não são capazes de garantir uma efetiva e integral participação da comunidade na elaboração do Projeto. A participação também sofre o efeito de diversos fatores e é um plano em disputa, tendo em vista o interesse de diferentes grupos envolvidos: o Estado, as indústrias, a Universidade, os/as jovens. De nossa parte, o exercício fundamental foi manter a conexão com os princípios ético-políticos da pesquisa-intervenção em psicologia, dos estudos feministas e de gênero. E com relação a/os jovens, atentamos para a linha tênue entre a convocação à participação e a responsabilização ou disciplinamento deles/delas.

Isto posto, para adentrarmos mais especificamente no contexto do Ação Juvenil, apresentamos os/as interlocutores/as desse grupo de jovens. Participaram da pesquisa-intervenção 20 jovens, sendo 12 mulheres e 8 homens na faixa etária entre 16 e 20 anos, que se autodeclararam pardos (3), negros (9), morenos (4), brancos (4) e com os seguintes pertencimentos religiosos: evangélicos (6), protestantes (1), católicos (2), católico e evangélico (1) e sem religião (8).

Com base em uma leitura flutuante das transcrições e observação dos encontros vídeogravados, foi possível refletir quanto aos sentidos que os/as jovens construíam sobre sexualidade e sobre trabalho-lazer, mediados pelos processos grupais e pelas relações sociais. Escolhemos o tema como unidade de registro/de significação para análise, ou seja, o recorte foi construído a partir dos sentidos e não das formas, o que envolveu frases, sentenças, palavras, expressões, movimentos corporais, sempre contingenciados pelas entonações, marcadores sociais, singularidades do grupo e de cada interlocutor/a. Após algumas leituras das transcrições, selecionamos as questões mais relevantes e as agrupamos em categorias. A seguir traremos os recortes de análise dos 
momentos relacionados à sexualidade e aos cenários de trabalho-lazer.

\section{Droga, loucura e vício: vivências sexuais de mu- lheres jovens}

O trabalho com o tema sexualidade foi, para a nossa surpresa, mediado pela discussão acerca de incesto. Talvez a nossa surpresa-espanto fosse efeito do sentido de tabu que circunscreve essa prática sexual nos estudos psicanalíticos clássicos (Freud, 1913/1996), antropológicos (Strauss, 1976) e nos estudos que o tratam como violência sexual e trazem os "pactos de silêncio" (Martins \& Jorge, 2010) das famílias que o vivenciam.

O espaço grupal do Ação Juvenil construiu-se como privilegiado para conversar a respeito de questões ligadas à sexualidade. Esse espaço contribuiu para que, através dos 'toques' dos diálogos, os/as jovens se movimentassem com intensidade e multiplicidade sem, todavia, deixarem de se confundir e instaurarem conflitos.

Como comentamos anteriormente, o grupo de jovens do Ação Juvenil pertence a um território que conheceu um aclamado e suposto "desenvolvimento econômico" com a chegada da Refinaria Abreu e Lima. Nele, vulnerabilidades sociais relativas à violência de gênero, por exemplo, foram intensificadas. Assim, problematizar o excessivo otimismo com que "o desenvolvimento econômico brasileiro" muitas vezes tem sido comemorado (Mayorga \& Pinto, 2013) invisibilizando o histórico de desigualdade social, racismo e sexismo que não só permanece, como é agravado junto a ele, era propósito da pesquisaintervenção. Esse otimismo invisibilizador contagiou, inclusive, o grupo de jovens de forma geral: poucos pensavam a chegada da Refinaria com criticidade, no sentido de apenas compreendê-la como "algo muito bom para a Região", que chegou para "oferecer muitos empregos", ainda que majoritariamente ocupados por pessoas de fora da região, como contaram sem, entretanto, atribuir um caráter negativo a tal fato.

Essa especificidade territorial é importante de ser relembrada porque a discussão sobre as questões em torno do livre exercício da sexualidade foi construída através dos comentários feitos pelo grupo referentes às intervenções de rua, ou seja, às atividades nas Caravanas da Cidadania, e aos encontros nas oficinas de formação.

Os comentários, produzidos no contexto de oficinas, foram centralizados na discussão levantada por uma moradora do território que disse que "tem mulher que abusa sexualmente de homem e que as mulheres não deviam reclamar que eles chegassem bêbados em casa". Alguns/as integrantes do grupo trouxeram que "o cara trabalha a semana todinha, chega o fim de semana, o cara não pode nem tomar uma?". Quando indagados/as se a bebida era uma droga, responderam que sim, e Lucas completou: "Mulher é droga, mulher! Quanto mais bebida!". "Tem homem que é viciado em mulher... só que mulher é uma droga boa". Dessa forma, a discussão sobre consumo do álcool e sexualidade se interseccionaram (Nogueira, 2011; Pisciteli, 2008) marcadamente por um padrão sexista que igualava a mulher a um objeto potencialmente viciante assim como o álcool.

Para provocar intervenções, buscamos a estratégia de exotizar o campo, estranhá-lo para depois nos familiarizamos com ele (Da Matta, 1978). Apesar de compartilharmos sentidos de uma mesma cultura, e a própria equipe ser formada também por jovens, não podíamos perder a dimensão das especifidades daquele grupo de jovens não universitários. Dentro daquele grupo, portanto, era necessário pluralizarmos o olhar, e não apenas simplesmente acrescentando teoricamente um "s" na palavra "juventudes". Ou seja, era necessário tentarmos reconhecer as diferenças e identificar desigualdades entre eles e elas (Mayorga \& Pinto, 2013), além de problematizarmos o ruído que poderia estar sendo produzido entre nós da equipe e o restante do grupo. Afinal, o que existe não é uma suposta universalidade na linguagem, mas sim um "concurso de dialetos" (Deleuze \& Guatarri, 1995).

Pensamos, então, se não se tratava de um "dialeto" que nós não havíamos compartilhado naquela cadeia semiótica que aglomerava várias vozes, vários referenciais. Assim, questionamos: "Perai!! $O$ que é um homem viciado em mulher que ainda não entendi?". Diego respondeu: "É homem safado!". Luiz completou: "Homem raparigueiro!". Raissa (facilitadora): "Homem safado, e homem safado quer o quê?". Sabrina contou: "Sexo!" Raissa (facilitadora): "Sexo... ah então peraí... a gente tá falando de vício em sexo... ou tá falando de vício em mulher?". Sabrina completou: "Vício em tudo..."; Evelyn colocou: "Vicio em sexo com mulher!", numa espécie de "conclusão" que satisfez o grupo. Raissa (facilitadora): "O que é sexo?". Diego disse: "Uma ação!"; Lucas riu: "Uma ação e uma reação, né?". O grupo concordou e todos nós achamos graça juntos.

Essa questão da "ação e reação" nos pareceu ter sido a forma como o grupo tocou na dimensão da atração sexual, ou ainda do prazer sexual como algo contínuo. Isto é, os/as jovens trouxeram essa "lei da física" para ilustrar a dimensão compartilhada do prazer sexual, em que a satisfação é inevitavelmente 
transitória (Parker, 1991). Transitam forças e intensidades, entre os corpos e prazeres nas mesmas direções; tais corpos podem ainda agir e reagir de forma criativa, por meio da construção de diferentes sentidos, opostos ou não, para a prática sexual. Deste modo, a lei da "ação e reação" funcionou como uma metáfora para falar de desejo, excitação e ciclos vivos das atrações entre os corpos.

Raissa (facilitadora): "Então vocês estão falando que existem homens viciados em sexo?". "E!'", afirmaram. Raissa (facilitadora): "E existem mulheres viciadas em sexo?". "Tem!!!", enfatizaram. Charlii levantou a mão: "É... Passou uma notícia na televisão... essa semana ou foi semana passada... a mulher saiu no meio da rua... ela era doida por sexo e saiu comendo todo mundo que via pela frente!" (sic). Aline e Andréa taparam a boca com as mãos, escandalizadas. Diego estranhou: "A mulher comendo?" (sic).

Esse estranhamento de Diego pode estar ligado ao fato de que, para ele, a mulher só "dá", ela não "come", já que os prazeres do paladar são associados simbolicamente aos prazeres sexuais; e, portanto, a mulher, para Diego, não seria necessariamente sujeito sexual, e sim objeto: o próprio prato de comida (Parker, 1991). Aliás, está claro que não só Diego pensava dessa forma: essa ideia faz parte do repertório erótico brasileiro ligado às questões de gênero, estando também presente no grupo do Ação Juvenil. $\mathrm{Na}$ cultura brasileira, desejo sexual é sinônimo de apetite sexual; apetite em que o objeto sexual é relacionado ao conceito de comida, e ao ato sexual, o de comer. Assim, a extensão na qual as noções de "comer" e "dar de comer", por exemplo, participam das hierarquias de gênero.

No entanto, o simbolismo do gênero também pode se transformar na linguagem do erótico. Assim o fez Charlii: "transformou" a hierarquia de gênero no seu enunciado, além de justificar a sua analogia como justamente algo comum, uma vez que assim falamos cotidianamente: " $E$, comendo, modo de falar, né, assim?". Raissa (equipe) o encorajou a continuar: “Arram!'(sic). Foi aí que Charlii disse: "Teve outra mulher também que pegou a família toda: pegou o primo, o pai, o irmão, o sobrinho, os vizinhos" (sic).

Charlii encerrou sua fala com a pergunta: "Isso é uma doença, ou é safadeza dela?". "É um vício!", disseram Sabrina e José. Foi aí que refletimos que o vício podia representar para o grupo uma união entre aqueles dois significantes: "doença e safadeza". Os limites entre tais significantes são bem tênues. Tratar um vício é difícil porque, como profissionais da área psicossocial, apesar de responsabilizarmos os sujeitos, jamais devemos julgá-los moralmente. Contudo, era esse julgamento moral que estava sendo feito ali. E foi aí também que questionamos: " $E$ isso aí que Charlii estava falando de ela fazer sexo com os familiares, como é que é isso pra vocês?". Evelyn respondeu prontamente: "Ai ela já é doida, né?". Facilitadora: "Ela é doida?". Evelyn, Sabrina, José, Diego falaram: "É doida!".

Como se, caso fosse "doente", a pessoa que praticasse o incesto pudesse ter uma "justificativa", no sentido de que o sujeito padeceria de um "mal" e não teria controle sobre ele. Ao doente, o "perdão"; aos "safados" e "safadas", praticantes da "safadeza", não; afinal, poderiam ter suas satisfações sexuais de forma comuns, convencionais, tidas como saudáveis. Havia uma possibilidade de escolha para aqueles praticantes da "safadeza", diferentes dos "doentes". Já no caso de ser "safadeza", não havia justificativa legítima aparente para a prática incestuosa. A partir da pergunta de Charlii: "Isso é doença ou é safadeza dela?", tampouco compreendemos "safadeza" como algo positivado da ordem do erótico. Soou mais como algo aproximando a ideia de "maldade", "pouca vergonha" "perversão", "malícia".

Dentro do sistema de referência erótico, a ideia de "safadeza" e/ou "sacanagem" implica desobediência, pode envolver um prazer dissidente, uma prática fora da ordem. Nas tentativas de respostas do grupo, apareceu o sentido da doença mental, da loucura: " $a i$ ela já é doida, né?". A ideia de vício deslizou para a ideia de loucura, ligada ao marcador de gênero. Isso porque, quando o grupo trouxe a questão do "homem viciado em mulher", depois transformado em "homem viciado em sexo com mulher", em nenhum momento este suposto homem foi denominado como louco. Aparentemente, "um homem viciado em sexo com mulher" - vê-se a reprodução do padrão heteronormativo - é algo não só "normal", posto que ele não é "louco" e/ou "anormal", como também esperado: a potência sexual masculina é suposta e até devidamente tão grande e incontrolável que esse homem pode se viciar em sexo - sexo heteroafetivo - sem precisar ter alguma "doença mental" para tal.

Já a "mulher viciada em sexo", sim, é doente, louca. Afinal, há um campo em comum entre a sexualidade feminina e a loucura (Zanello \& Silva, 2012); além de uma espécie de pertinência dessa sexualidade à doença quando a mesma se torna um "vício". Assim, a sexualidade feminina que ainda é tida, muitas vezes, como tabu, e aquelas vivências que fogem aos padrões exogâmicos, foram significadas como tão desviantes e dissidentes para o grupo quanto a loucura institucionalizada. Houve, portanto, um 
julgamento moral diferente do grupo para tratar das "mulheres viciadas em sexo" e dos "homens viciados em sexo".

Sabemos que a Psiquiatria e a Psicologia historicamente se ocupam das irregularidades sexuais intrafamiliares para, inclusive, explicar modelos de (des)estruturações psíquicas (Foucault, 2010). Para o grupo do Ação Juvenil, tais ciências deveriam se ocupar dessas irregularidades apenas quando "cometidas" por mulheres. Mas de nenhum tratamento ou punição era preciso se ocupar do "homem heterossexual", aquele "simplesmente viciado em sexo com mulher". As dificuldades do grupo foram, por conseguinte, de desnaturalizar a suposta potência sexual incontrolável do homem direcionada à mulher, e de conceber a mulher como simplesmente possível transgressora sexual e/ ou não doente; sentidos, acreditamos, intensificados pelo tabu da sexualidade feminina e pelo imperativo heteronormativo.

Entre o trabalho e o direito ao lazer: variações em torno da dicotomia público (masculino)-privado (feminino)

Em uma oficina aos moldes de roda de conversa, sobre a relação entre consumo de álcool e lazer, curiosamente, o debate tomou forma a partir do contraponto lazer-trabalho, mediante relações de gênero e correlatas tensões entre público e privado. O consumo de álcool, como uma forma de desfrutar do tempo livre para o lazer, foi problematizado pelo grupo como um direito, tensionado nas desigualdades vivenciadas por mulheres e homens nas relações entre trabalho produtivo e trabalho doméstico.

Conforme trazido pelo grupo, a tensão públicoprivado se apresenta para meninos e meninas desde a família, quando educações diferentes são dadas aos e às filhos/as. Segundo Saory, seu irmão Charlii tinha sempre mais liberdade de estar na rua: “... sempre tinha essa desigualdade. É mais fácil pro homem sair do que pra mulher sair. Quando a mulher sai, não tem mais nem graça.", referindo-se à possibilidade de mulheres vivenciarem situações de lazer em espaços públicos.

Saory, Taís e Charlii entraram em discussão quando este último explicou tal diferença diante do fato, de acordo com ele, de as mulheres serem frágeis. Saory questionou o jovem:

Então quer dizer que a mulher tem que ficar em casa pro homem trabalhar? Ai, nem sabe se ele tá trabalhando mesmo... Chega em casa cansado, a mulher esperando, ai ele :"vou dormir", deita e dorme. ... Se fosse frágil [referindo-se à mulher], não fazia tanta coisa de uma vez só em casa. Que a mulher não faz uma coisa só. Tá com uma panela no fogão, lavando prato, lavando roupa... Cuidando de menino, que pode tá correndo não sei pra onde.

Intervimos: "Vocês tão dizendo, então, que têm direitos iguais: mulheres vão pra rua e homens também. Mas que, na prática, não é bem assim, né, pelo que vocês tão dizendo?" (Leyllyanne - facilitadora). O grupo concordou, e a co-facilitadora continuou: "Então... tem vantagens e desvantagens em trabalhar fora e dentro de casa?". Charlii respondeu:

É porque o maior trabalho é o da mulher, né... porque o do homem... pode trabalhar quantas horas for, até sem parar. Chegou em casa, come, tomou um banho... ou vai assistir ou vai dormir. Mulher não. Mulher acorda cedo, faz isso, faz aquilo, faz isso, faz aquilo, faz isso, faz aquilo. O marido chega, ai fazer aquilo de novo, isso de novo, de novo...

As/os jovens tenderam a caracterizar as relações entre as esferas doméstica e profissional fazendo referência a um "modelo tradicional", em que o lugar de provedor da família é atribuído ao homem, enquanto que os lugares referentes ao trabalho doméstico e aos cuidados com a família são cabidos às mulheres. Tal modelo pode ser pensado na relação com o território a partir do legado do patriarcado ${ }^{4}$ na região Nordeste salientando-se aí a região Suape que, até recentemente, teve sua economia voltada, sobretudo, à monocultura de cana-de-açúcar. Conforme os relatos trazidos e as experiências compartilhadas no grupo, trata-se de um forte organizador da vida, também em termos de quais corpos ocupam quais lugares na/da cidade, estes considerados segundo a categorização público/ privado. Tal organização tende a se dar através do marcador gênero, que ainda acaba por circunscrever maiores possibilidades/dificuldades de relação com os/nos espaços públicos e privados para homens e mulheres.

Perguntamos ao grupo: "Vocês acham que é trabalho isso que as mulheres fazem em casa?" (Leyllyanne). Charlii falou: "As mulheres não têm folga não". Saory, por sua vez, comentou: "No final de semana, o cara diz... 'vou ali tomar uma com a rapaziada'... Vai simbora... e a mulher fica em casa... cuidando dos meninos". Associada às maiores liberdades, em geral, conferidas ao homem, práticas de consumo alcoólico, no contexto da relação conjugal, podem ser caracterizadas tomando a divisão desigual do tempo livre para mulheres e homens, em sentido quantitativo e qualitativo: os homens, em geral, acabam possuindo quantidades maiores de tempo livre, que podem ser dedicadas ao lazer e, assim, tendem a ter mais momentos de fruição, a exemplo do consumo de 
bebidas alcoólicas em espaços públicos da cidade, tais como os bares.

Tais vivências de lazer, como forma de aproveitar o tempo livre, parecem se colocar para os homens como algo legítimo diante do tempo gasto no trabalho produtivo, funcionando como uma espécie de recompensa à garantia do provimento. Uma das facilitadoras interveio, questionando se essa organização, que coloca o homem como responsável pelo dinheiro e a mulher pela casa, estava bem da forma como tem se dado, ou se achavam que poderia ser diferente.

Esse foi um momento de tensões entre os/ as jovens no grupo. Todos/as ficaram em silêncio diante da pergunta, até que se configuraram dois posicionamentos: o grupo dos meninos, satisfeitos com a forma posta de organização; e o grupo das meninas, insatisfeitas e demandando mudanças. Salientamos que as jovens só falaram dessa insatisfação depois que as questionamos uma por uma, o que nos comunica sobre as relações de poder entre mulheres e homens estabelecidas no grupo: mesmo em maioria quantitativa, não foi simples para as jovens se posicionarem diante de tal questão.

Charlii argumentou acerca de um suposto equilíbrio estabelecido pela forma como têm funcionado as relações entre homens e mulheres na família: "As pessoas estão tão acostumadas com esse equilibrio de homem trabalhar e mulher ficar em casa... se os dois sairem, vai ser como... se tivesse uma explosão... Porque homem não quer que mulher trabalhe". Esse equilíbrio remete a um padrão sociocultural que, a partir de normas regulatórias de gênero, circunscrevem guias para a constituição de homens e mulheres, incluindo-se aí as formas de usar o tempo, a divisão do trabalho (re)produtivo e o direito ao lazer relativo aos espaços públicos e privados. Deslocamentos nessa estrutura organizativa parecem poder gerar tensões significativas, ao menos segundo a perspectiva de homens, tendo sido comparados por Charlii a uma "explosão".

Como contraponto a esse posicionamento, algumas jovens compartilharam exemplos de possibilidades de mudanças. Raiane disse que conhece um casal diferente: "O homem quer que a mulher trabalhe e... ele quer ficar em casa, cuidando dos filhos. As pessoas, assim, acham estranho, né? Ele ficou um ano cuidando das filhas, normal, enquanto ela tava trabalhando. Ele ia fazer a feira... fazia tudo". Saory, por sua vez, comentou: "As pessoas dizem que um cara é meio estranho quando ele sabe fazer tudo dentro de casa... começa a tirar onda... dizendo que é gay”. Referiu-se a cobranças das pessoas de que a mulher é quem deveria ficar mais em casa, e não ele.

Ainda a respeito desse estranhamento, Raiane o afirmou como algo positivo e produtivo:

Eu acho, assim, que... causar estranhamento é até melhor porque... As pessoas de alguma forma vão se tocar... E assim, tem que aceitar porque... Elas não vão poder mudar o que as outras pessoas querem. Agora, tipo, como Charlii tava falando... Se todo mundo pensar assim, que é normal, aí... Esse é o problema, todo mundo pensar do mesmo jeito, pensar de forma errada. E, se a gente, que... pensa desse jeito, mobilizar, ai vai mudar, ai a gente consegue mudar. Mas se a gente pensar todo mundo da mesma forma, aí não consegue.

Como trazido por essa jovem, a produção da diferença como alteridade se coloca quando é possível tecer enredos para além do roteiro pré-estabelecido. Os exercícios recíprocos de estranhar o familiar e de familiarizar o estranho são basilares para a construção de conhecimento e para a compreensão do outro como diferente. Também é fundamental para se vislumbrar e se efetivar modos de relações interpessoais e sociais mais justas, comprometidas com experiências de diferença e enfrentamento das desigualdades.

A participação das jovens Saory e Raiane foi de grande importância para movimentos de questionamentos, o que teve relevantes efeitos para o grupo em termos de desestabilização de discursos normativos sobre as relações de gênero. São exemplos a sinalização de desigualdades entre mulheres e homens relativas ao desempenho do trabalho doméstico e o correlato direito ao tempo livre para o lazer; assim como o direito das mulheres de desfrutar seu tempo livre mediante o consumo de álcool, caso seja de sua vontade, sem precisar ser alvo de fofoca, julgamentos, punições e outras formas de violências experienciadas na comunidade.

\section{Considerações sobre os posicionamentos epistemológicos e metodológicos na pesquisa- intervenção feminista}

Buscamos, nessas considerações finais, enfatizar a importância do diálogo entre a Psicologia e as Teorias Feministas, a partir do debate epistemológico e metodológico acerca do direito à pesquisa e da noção de pesquisa participativa com grupos em contexto de desigualdades. Neste percurso, as posições de pesquisadoras e de participantes vão se deslocando, bem como aponta a literatura na área (Fine, 2015), 
e os lugares de privilégios (ser pesquisador e ter acesso ao conhecimento acadêmico) passam a se comunicar com as posições das/os participantes (que conhecem seu território, sua vizinhança melhor que ninguém), de forma tal que distintos conhecimentos se agregam, permitindo a produção de pesquisa e de intervenção. Reflete-se e atua-se sobre a realidade social interseccional desigual.

Vivenciamos um desmanche dos lugares de quem ensina e de quem aprende, desmanche que faz parte da dimensão participativa das oficinas como tecnologias sociais. Aprendemos com o grupo que, claro, há limites para o que pode e/ou é possível ser dito ou não nos encontros, tendo em vista os diversos fatores envolvidos na relação pesquisador/a e interlocutores/ as, guardados pelas próprias diferenças subjetivas atreladas a gênero, classe e território entre nós. No entanto, não podemos antecipar tais limites com exatidão, nunca prevemos exatamente o que vai surgir. Essa imprevisibilidade relacionada a um contexto em que discutíamos sobre sexualidade, território, classe, gênero favoreceu a fluidez com que as agendas de debate surgiram. Além disso, possibilitou a discussão relacionada a temas ligados a distintas desigualdades, junto com os/as jovens, visto que muitas vezes estes/ as têm seus saberes sobre eles/elas desqualificados e estigmatizados (Mayorga \& Pinto, 2013; Parker \& Manir, 2009).

Estas questões corroboraram com a legitimidade que o trabalho de pesquisa-intervenção Ação Juvenil foi conquistando ao longo do tempo. Muitos/as jovens sinalizaram, inclusive, em momentos de oficinas e conversas nos "corredores", que ali era o único lugar onde podiam falar abertamente a respeito "dessas coisas" - referindo-se às questões associadas às suas demandas e agendas, tais como sexualidade e uso de álcool.

Tais reverberações consolidam nossa aposta nas metodologias participativas e nas epistemologias feministas e pós-estruturais como deslocamentos necessários ao campo psi.

\section{Notas}

1 As "Caravanas da Cidadania" também fizeram parte do Projeto Diálogos e tinham como objetivo contribuir para a formação dos técnicos dos serviços da rede municipal de saúde, assistência e educação, promovendo uma mobilização comunitária por meio de intervenções desses atores, além dos/as jovens do Ação Juvenil, somada à equipe universitária.

2 Considera-se grupo de formação o coletivo composto tanto por jovens quanto pelos/as pesquisadores/as.
3 Os nomes são "fictícios" e foram escolhidos pelos/as jovens participantes do projeto. Já a equipe da universidade (estudantes de graduação e pós-graduação e professoras) autorizou a exposição de seus "nomes reais".

$4 \mathrm{O}$ conceito de patriarcado, útil do ponto de vista da mobilização política, colocou problemas à compreensão da historicidade de uma "condição feminina"; com o tempo, o patriarcado passou a ser uma espécie de conceito vago, sinônimo de sistema de opressão masculina, tratado, por vezes, como uma essência (Piscitelli, 2004). Daí, a necessidade do cuidado de tratá-lo sempre como fenômeno contingente e histórico.

\section{Referências}

Abramo, H. (2005). Condição juvenil no Brasil contemporâneo. In H. W. Abramo \& P. P. M. Branco (Orgs.), Retratos da juventude brasileira: análises de uma pesquisa nacional (pp. 37-72). São Paulo: Fundação Perseu Abramo; Instituto Cidadania.

Adrião, K. (2014). Perspectivas feministas na interface com o processo de pesquisa-intervenção-pesquisa com grupos no campo psi. Labrys, coletânea feminismos e psicologia, 26, 79-93.

Butler, J. (2004). Undoing Gender. New York: Routledge.

Carrano, P. (2000). Juventudes: as identidades são múltiplas. Revista Movimento,

Faculdade de Educação da UFF, 2(1) 11-27.

Costa, J. F. (1989). Psicanálise e contexto cultural. Rio de Janeiro: Campus.

Costa, J. F. (2002). Os amores que não se deixam dizer. In $A$ inocência e o vício: estudos sobre o homoerotismo (pp. 4157). Rio de Janeiro: Relume Dumará.

Da Matta, R. (1978). O ofício de etnólogo ou como ter “Anthropological Blues". In

E. O. Nunes (Org.), A aventura sociológica (pp. 23-25). Rio de Janeiro: Zahar.

Deleuze, G. \& Guatarri, F. (1995). Introdução: Rizoma. In Mil platôs: capitalismo e esquizofrenia 2 (Vol. 1, pp. 17-49). São Paulo: Editora 34.

Fine, M. (2015). Glocal provocations:critical reflections on community based research and intervention designed at the (glocal) intersections of the global dynamics and local cultures. Community Psychology in Global Perspective. $C P G P, 1(1), 5-15$.

Fine, M. \& Fox, M. (2013). A prática da liberdade: pesquisa de ação participativa da juventude para a justiça na educação. In J. A. Menezes, M. R. Costa, \& T. C. S. Araújo (Eds.), JUBRA: territórios interculturais de juventude (pp. 365382). Recife: Editora Universitária da UFPE.

Fine, M. \& McClelland, S. (2007). The politics of teen women's sexuality: Public policy and the adolescent female body. Emory Law Review, 56(4) 993-1038.

Fine, M., Weis, L., Weseen, S., \& Wong, L. (2006). Para Quem? Pesquisa qualitativa, representações e responsabilidades sociais. In N. Denzin \& Y. Lincoln (Orgs.), O planejamento da pesquisa qualitativa:teorias e abordagens (pp. 115-140). Porto Alegre: Artmed.

Foucault, M. (2006). Microfisica do poder ( $8^{\mathrm{a}}$ ed.). Rio de Janeiro: Graal. 
Foucault, M. (2010). Os anormais. São Paulo: Martins Fontes.

Freud, S. (1996). Totem e Tabu e outros trabalhos. In Edição Standard Brasileira das Obras Completas de Sigmund Freud (Vol. 13, pp. 7-18). Rio de Janeiro: Imago. (Original publicado em 1913-1914)

Haraway, D. (1995). Saberes Localizados: a questão da ciência para o feminismo e o privilégio da perspectiva parcial. Cadernos Pagu, 5, 07-41.

Martins, C. B. G. \& Jorge, M. H. P. M. (2010). Abuso sexual na infância e adolescência: perfil das vítimas e agressores em município do sul do Brasil. Texto \& Contexto, Enfermagem, 19(2), 246-255.

Mayorga, C. \& Pinto, G. P. (2013). Juventudes: a pluralização da experiência ou a invisibilidade das relações de poder. In J. A. Menezes, M. R. Costa, \& T. C. S. Araújo (Eds.), JUBRA: territórios interculturais de juventude (pp. 101-114). Recife: Editora Universitária da UFPE.

McCarthy, J. Galvão, K. (2001) Um recurso para o teatro, participação e desenvolvimento. Recife: Projeto ARTPAD.

Menezes, J. A., Costa, M. R., \& Araújo, T. C. S. (2013). JUBRA: territórios interculturais de juventude. Recife: Editora Universitária da UFPE.

Neves, S. \& Nogueira, C. (2003). A psicologia feminista e a violência contra as mulheres na intimidade: a (re)construção dos espaços terapêuticos. Psicologia \& Sociedade, 15(2) 4364.

Nogueira, C. (2011). Introdução à teoria da interseccionalidade nos estudos de gênero. In S. Neves (Org.), Gênero e Ciências Sociais (pp. 67-78). Lisboa: Edições ISMAI.

Palombini, A, Maraschin, C., \& Moschen, S. (2012). Tecnologias em rede. Oficinas de fazer saúde mental. Porto Alegre: Sulina.

Paiva, V. (2002). Sem mágicas soluções: a prevenção ao HIV e à AIDS como um processo de "emancipação psicossocial". In R. Parker \& V. Terto (Orgs.), Anais do seminário: prevenção à AIDS: limites e possibilidades na terceira década (pp. 2026). Rio de Janeiro: ABIA.

Parker, R. (1991). Homens e Mulheres. In Corpos, prazeres e paixões: a cultura sexual no Brasil Contemporâneo (pp. 55107). São Paulo: Best Seller.

Parker, R. (1998). Teorias de intervenção e prevenção do HIV/ AIDS. In R. Parker \& V. Terto (Orgs.), Entre Homens: homossexualidade e AIDS no Brasil (pp. 101-109). Rio de Janeiro: ABIA.

Parker, R . \& Manir, M. (2009). No carrossel da pedofilia. In J. A. Menezes \& L. F. Rios (Orgs), Violência sexual contra crianças e adolescentes (pp. 19-24). Recife: Editora Universitária da UFPE.

Piscitelli, A. (2004). Reflexões em torno do gênero e feminismo. In C. L. Costa \& S. P. Schmidt (Eds.), Poéticas e políticas feministas (pp. 02-15). Florianópolis: Editora Mulheres.

Piscitelli, A. (2008). Interseccionalidades, categorias de articulação e experiências de migrantes brasileiras. Sociedade e Cultura, 11(2), 263-274.

Quadros, M. T., Adrião, K. G., \& Xavier, A. K. (2011). Circuitos (des)integrados? Relações de convivência entre mulheres jovens e profissionais de saúde numa comunidade de periferia da cidade do Recife (PE). In P. Nascimento \& L. F. Rios (Orgs.), Gênero, saúde e práticas profissionais (pp. 97-113). Recife: Editora Universitária da UFPE.
Serafim, T. \& Bonini, L. G. (2015). Reflexões sobre juventude brasileira e engajamento político-social - Lúcia Rabello de Castro. Revista NUPEM, 7(12), 11-19.

Strauss, L. (1976). Os princípios do parentesco. In As estruturas elementares de parentesco (pp. 519-537). Petrópolis, RJ: Vozes.

Toneli, M. J., Adrião, K., \& Perucchi, J. (2013). Gender and feminisms: Theoretical-epistemological considerations and methodological impacts. Psicologia \& Sociedade, 25 (n. spe.), 1-2.

UFPE-FADE. (2011). Diálogos para o Desenvolvimento Social em Suape. Desenvolvimento \& Cidadania Petrobras. Referente ao projeto desenvolvido pelo Departamento de Psicologia do Centro de Filosofia e Ciências Humanas. Recife: Autores.

Zanello, V. \& Silva, R. M. C. (2012). Saúde mental, gênero e violência estrutural. Revista Bioética, 20(2), 267-279.

\section{Agradecimentos}

Às agências de fomento: Coordenação de Aperfeiçoamento de Pessoal de Nível Superior (CAPES) - bolsa de estágio pós-doutoral/Processo $\mathrm{n}^{\circ}$ 1783-14-9 (Karla Galvao Adriao). Conselho Nacional de Desenvolvimento Científico e Tecnológico (CNPQ) - projeto diálogos (pool de agências privadas da região em desenvolvimento de Suape-PE), coordenação geral Prof. Dr. Luis Felipe Rios do Nascimento (CFCH/ UFPE).

Submissão em: 28/08/2015

Revisão em: 30/12/2015

Aceite em: 28/04/2016

Karla Galvão Adrião é docente do Departamento e do Pós-graduação em Psicologia da UFPE, pesquisadora do LabEshu (Laboratório de Estudos da Sexualidade Humana). Atua na interface entre os campos da psi clínica e social, a partir de referencial feminista pós-estrutural e descolonial. Temas de interesse: direitos sexuais e direitos reprodutivos, direito ao conhecimento e direito à cidade, trabalho com grupos e juventude.

Endereço: Av da Arquitetura, s-n, $9^{\circ}$ andar. Depto de Psicologia, Centro de Filosofia e Ciencias Humanas, UFPE. CEP 50740550, Recife/PE, Brasil. E-mail: galvaoadriao@gmail.com

Jaileila de Araújo Menezes é psicóloga (UFC), mestra e doutora em Psicologia (UFRJ). É professora do Departamento de Psicologia e Orientações Educacionais do Centro de Educação e do Programa de Pós-graduação em Psicologia (UFPE). Pesquisadora do Grupo de Estudos e Pesquisas sobre Poder, Cultura e Práticas Coletivas (GEPCOL). Investiga questões relativas à Juventude e Movimentos Sociais, Juventude e Participação, Juventude e Projeto de Vida.

E-mail: jaileila.araujo@gmail.com 
Raissa Falcão é psicóloga (UFPE) com atuação na área clínica. Mestra em Psicologia pela UFPE e docente da Faculdade Estácio do Recife - FIR. Pesquisadora vinculada ao Laboratório de Estudos sobre Sexualidade Humana LABESHU/UFPE. Tem interesse nas áreas de juventude, sexualidade, gênero e feminismo.

E-mail: raissa.falcao@encontrartepsi.com.br

Leyllyanne Bezerra de Souza é psicóloga (UFPE), com atuação na área clínica e educacional, mestra em Psicologia (UFPE). Professora substituta no Departamento de Psicologia e Orientações Educacionais do Centro de Educação da UFPE. Pesquisadora vinculada ao Grupo de Estudos e Pesquisas sobre Poder, Cultura e Práticas

Coletivas (GEPCOL). Tem interesse nas áreas de juventude, álcool e outras drogas, gênero e feminismo.

E-mail: leyllyanne@hotmail.com 